\title{
Molecular Analysis of a Female Lesch-Nyhan Patient
}

\author{
Nobuaki Ogasawara, ${ }^{\star \ddagger} \mathrm{J}$. Timothy Stout, ${ }^{5}$ Haruko Goto, ${ }^{\star}$ Shin-Ichi Sonta, ${ }^{\ddagger}$ Akiko Matsumoto," and C. Thomas Caskey \\ Departments of ${ }^{*}$ Biochemistry and ${ }^{\ddagger}$ Genetics, "Institute for Developmental Research and Pediatric Neurology, Central Hospital, \\ Aichi 480-03, Japan; and $\$$ Institute for Molecular Genetics and Howard Hughes Medical Institute, \\ Baylor College of Medicine, Houston, Texas 77030
}

\begin{abstract}
We report the identification of a female patient with the $X$ linked recessive Lesch-Nyhan syndrome (hypoxanthine phosphoribosyltransferase [HPRT] deficiency). Cytogenetic and carrier studies revealed structurally normal chromosomes for this patient and her parents and demonstrated that this mutation arose through a de novo gametic event. Comparison of this patient's DNA with the DNA of her parents revealed that a microdeletion, which occurred within a maternal gamete and involved the entire HPRT gene, was partially responsible for the disease in this patient. Somatic cell hybrids, generated to separate maternal and paternal $X$ chromosomes, showed that expression of two additional $\mathrm{X}$-linked enzymes, phosphoglycerate kinase and glucose-6-phosphate dehydrogenase, were expressed only in cells that contained the maternal $X$ chromosome, suggesting the presence of a functionally inactive paternal $X$ chromosome. Furthermore, comparison of methylation patterns within a region of the HPRT gene known to be important in gene regulation revealed differences between DNA from the father and the patient, in keeping with an active HPRT locus in the father and an inactive HPRT locus in the patient. Together these data indicate that nonrandom inactivation of the cytogenetically normal paternal $X$ chromosome and a microdeletion of the HPRT gene on an active maternal $X$ chromosome were responsible for the absence of HPRT in this patient.
\end{abstract}

\section{Introduction}

The identification of females with $\mathrm{X}$-linked recessive disorders has been reported for numerous single gene defects including deficiencies of dystrophin (Duchenne muscular dystrophy), Factor VIII (hemophilia A), and Factor IX (hemophilia B) (1-5). The expression of these phenotypes in females commonly occurs in association with cytogenetic abnormalities, including 45:XO (Turner's syndrome) and X:autosome translocations. Such cytogenetic alterations favor the disease state by interrupting sequences important to gene expression or by promoting nonrandom $\mathrm{X}$ inactivation. Nonrandom inactivation of structurally abnormal $\mathrm{X}$ chromosomes has been well documented and presumably minimizes the deleterious affects

Address correspondence to Dr. J. Timothy Stout, Institute for Molecular Genetics and Howard Hughes Medical Institute, Baylor College of Medicine, One Baylor Plaza, Houston, TX 77030.

Received for publication 26 October 1988 and in revised form 11 April 1989.

\footnotetext{
J. Clin. Invest.

(c) The American Society for Clinical Investigation, Inc.

0021-9738/89/09/1024/04 \$2.00

Volume 84, September 1989, 1024-1027
}

of gross chromosomal rearrangements $(4,6)$. We report the identification of a female with hypoxanthine phosphoribosyltransferase (HPRT) deficiency (the Lesch-Nyhan syndrome) whose disease resulted from a de novo deletion of the maternal HPRT gene and selection against, or nonrandom inactivation of, the paternal $\mathrm{X}$ chromosome.

HPRT deficiency is a disorder of purine metabolism characterized by hyperuricemia, choreoathetosis, spasticity, mental retardation, and self mutilation $(7,8)$. Functional HPRT is a 217 amino acid protein encoded by a single gene on the $X$ chromosome (Xq26-q27) $(9,10)$. The human gene is divided into nine exons that are dispersed over $\sim 44 \mathrm{~kb}$ of genomic DNA (11). Affected hemizygous males inherit the mutant allele from asymptomatic carrier females or are the result of de novo gametic mutations (12).

\section{Methods}

Cell culture. Lymphoblast cell cultures were established by EBV transformation of lymphocytes from peripheral blood of patients by standard methods. Cells were maintained in RPMI 1640 media that contained 10\% FCS (Gibco Laboratories, Grand Island, NY), penicillin $(100 \mu \mathrm{g} / \mathrm{ml})$, and streptomycin $(100 \mu \mathrm{g} / \mathrm{mg})$ at $37^{\circ} \mathrm{C}$ in $5 \% \mathrm{CO}_{2}$. Selection for HPRT ${ }^{-}$and $\mathrm{HPRT}^{+}$cells took place in media containing 6-thioguanine (6-TG) and hypoxanthine, aminopterin, and thymidine, respectively, as previously described $(13,14)$.

Southern blot analysis. Genomic DNA and cellular RNA were extracted by previously published protocols $(14,15)$. For Southern analysis DNA samples $(10 \mu \mathrm{g})$ were digested with $10-50 \mathrm{U}$ of a restriction endonuclease for $3 \mathrm{~h}$ under conditions specified by the supplier (Boehringer Mannheim Biochemicals, Indianapolis, IN). Digested DNA was fractionated through $0.8 \%$ agarose gels made in $1 \times$ TEA $(1 \times$ TEA $=0.04 \mathrm{M}$ Tris-acetate, $0.002 \mathrm{M}$ EDTA) at $40 \mathrm{~V}$ for $24 \mathrm{~h}$ and were transferred to nitrocellulose filters. HPRT cDNA or DXS-10 probes were labeled by nick-translation in the presence of $\left[\alpha-{ }^{32} \mathrm{P}\right] \mathrm{dCTP}$ under conditions specified by the supplier (nick-translation kit; Bethesda Research Laboratories, Gaithersburg, MD). Hybridizations were carried out under standard conditions. Washing of hybridized filters was performed at $65^{\circ} \mathrm{C}$ in $2 \times$ standard saline citrate, $0.1 \%$ SDS and autoradiography was performed at $-80^{\circ} \mathrm{C}$ with cronex intensifying screens (DuPont Instruments, Wilmington, DE).

Enzyme assays. Assays to measure HPRT activity used hypoxanthine-8- $\left[{ }^{14} \mathrm{C}\right]$ as substrate and adenine phosphoribosyltransferase activity was measured as an internal control in separate reactions using the substrate adenine-8-[ $\left[{ }^{14} \mathrm{C}\right]$. For glucose-6-phosphate dehydrogenase (G-6-PD) and phosphoglycerate kinase (PGK) studies extracts were prepared by sonicating frozen cells in the presence of $1 \mathrm{mM}$ NADP and $100 \mathrm{mM}$ Tris $\mathrm{HCl}(\mathrm{pH} \mathrm{8.0)}$. Electrophoresis and staining of G-6-PD and PGK activities were carried out as described previously $(16,17)$.

1. Abbreviations used in this paper: G-6-PD, glucose-6-phosphate dehydrogenase; HPRT, hypoxanthine phosphoribosyltransferase; PGK, phosphoglycerate kinase; 6-TG, 6-thioguanine. 


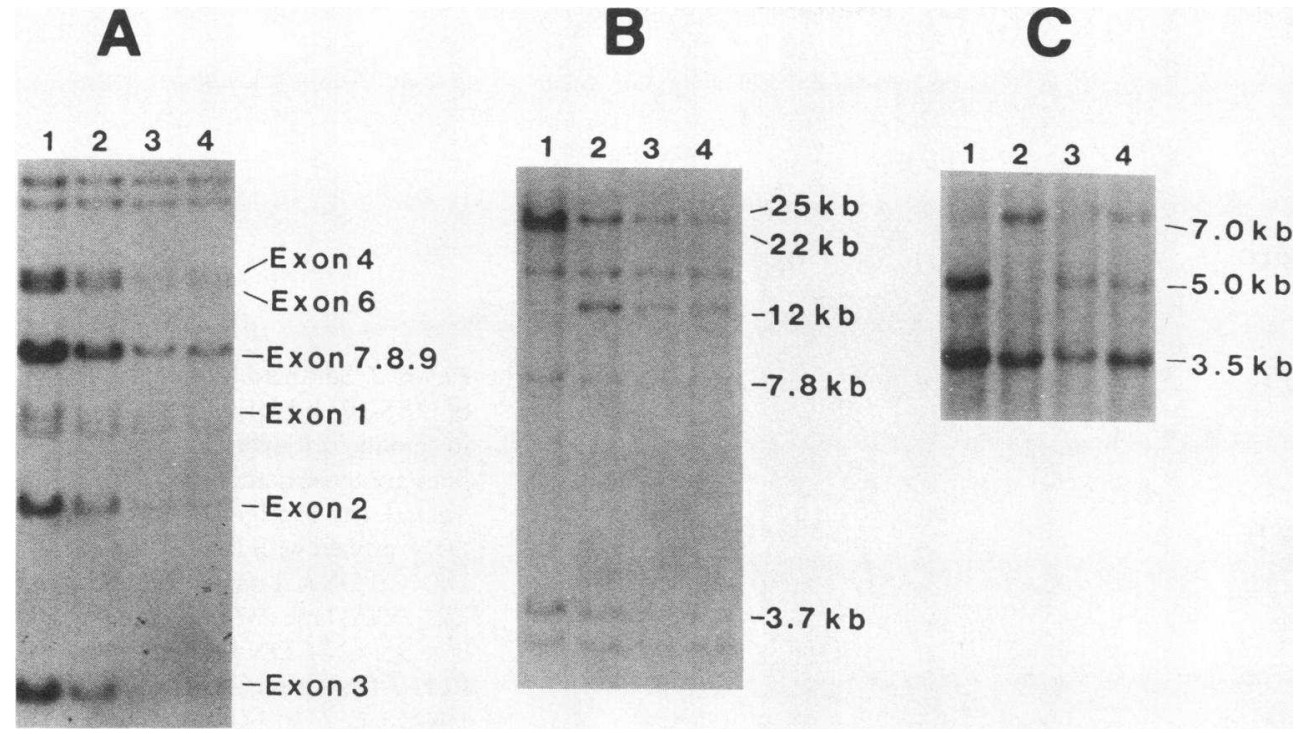

Figure 1. Southern analysis of genomic DNA from the female Lesch-Nyhan patient and her parents. $(A)$ Pst I-digested genomic DNA from an unrelated 48:XXXX female (lane 1), the mother of the Lesch-Nyhan patient (lane 2), the Lesch-Nyhan female patient (lane 3), and the father of the Lesch-Nyhan patient (lane 4). Filters were probed with labeled HPRT cDNA. (B) Bam HI-digested DNA from individuals as in $(A)$, hybridized with labeled HPRT cDNA. $(C)$ Taq I-digested DNA from individuals as in $(A)$, hybridized with labeled DXS- 10 .

\section{Results}

This patient presented at 9 yr of age with the typical biochemical and behavioral characteristics of the Lesch-Nyhan syndrome (18). Enzyme studies of fibroblasts and EBV-transformed lymphoblasts revealed a complete deficiency of HPRT and an ability to proliferate in media containing 6-TG (13), a purine analogue able to select for HPRT-deficient cells. High resolution analysis of chromosomes from the patient and her parents demonstrated normal karyotypes without evidence of mosaicism. Carrier studies of the mother found no HPRT ${ }^{-}$ hair follicles or 6-TG-resistant lymphoblasts or fibroblasts, suggesting that this patient's disease is a result of a de novo gametic mutation (19).

Southern analysis of maternal, paternal, and patient DNA demonstrated that a gametic deletion of a single HPRT gene was, in part, responsible for this patient's disease (Fig. 1, $A$ and $B)$. Genomic DNAs from members of this family were digested with Pst I $(A)$ and Bam $\mathrm{HI}(B)$ and probed with a fulllength HPRT cDNA $(14,20)$. The hybridization intensity of all exon bands were reduced in the affected female compared with her mother, but were equal to her father, suggesting that the patient carried an HPRT gene deletion. Densitometric comparison of X-linked exon signals with signals derived from autosomal pseudogenes confirmed hemizygosity at the HPRT locus for this patient. Northern and Western analysis of RNA and protein, isolated from fibroblasts from each member of this family, showed that while the patient failed to produce any detectable HPRT mRNA or protein, her mother and father synthesized normal amounts of appropriately sized message and protein (data not shown).

While the microdeletion in this patient involved the HPRT gene, it did not extend into the tightly linked, anonymous DXS-10 locus (Fig. $1 C$; reference 15). DNA from family members revealed that the mother was homozygous at the DXS-10 locus for the 7.0/3.5 alleles and the father was hemizygous for the 5.0/3.5 allele, while the patient was heterozygous for these alleles ( $7 / 5 / 3.5$ pattern). This polymorphism, in concert with somatic cell hybrids, was used to determine the parental origin of the microdeletion.
Somatic cell hybrids, derived by fusion of this patient's fibroblasts with thymidine kinase-deficient $\mathrm{HPRT}^{+}$mouse $\mathrm{L}$ cells, were generated to separate maternal and paternal $\mathrm{X}$ chromosomes. The DSX-10 restriction fragment length polymorphism was used to determine the presence of maternal or paternal X chromosomes in each hybrid cell line. Nine hybrid lines were studied; two clones contained both the maternal and paternal X chromosomes, six contained the paternal X chromosome alone, and one cell line contained only the maternal $\mathrm{X}$ chromosome (Table I). Southern analysis of the human HPRT gene sequences in these clones is shown in Fig. 2. As predicted by dosage analysis of DNA from the affected female (Fig. 1), a deletion of the HPRT gene was found and associated with the maternal $\mathrm{X}$ chromosome. The hybrid cell line with the single maternal $X$ chromosome contained no human $X$ linked HPRT gene sequences. Those clones that contained both the paternal and maternal X chromosomes were hemizygous for these sequences, as were those cells that contained only the paternal $\mathrm{X}$ chromosome. Thus, a microdeletion that occurred in a maternal gamete and involved the entire HPRT gene was partially responsible for the disease in this patient.

Table I. Summary of Chromosome and Enzyme Analysis in Somatic Cell Hybrid Clones

\begin{tabular}{ccc}
\hline Clones & Human X chromosome & $\begin{array}{c}\text { Human G-6-PD and } \\
\text { PGK expression }\end{array}$ \\
\hline FLN-1 & M and P* & + \\
FLN-2 & M and P & + \\
FLN-3 & P & - \\
FLN-4 & P & - \\
FLN-5 & P & - \\
FLN-6 & M & + \\
FLN-7 & P & - \\
FLN-8 & P & - \\
FLN-9 & P & - \\
\hline
\end{tabular}

* $M$, maternal; $P$, paternal. 


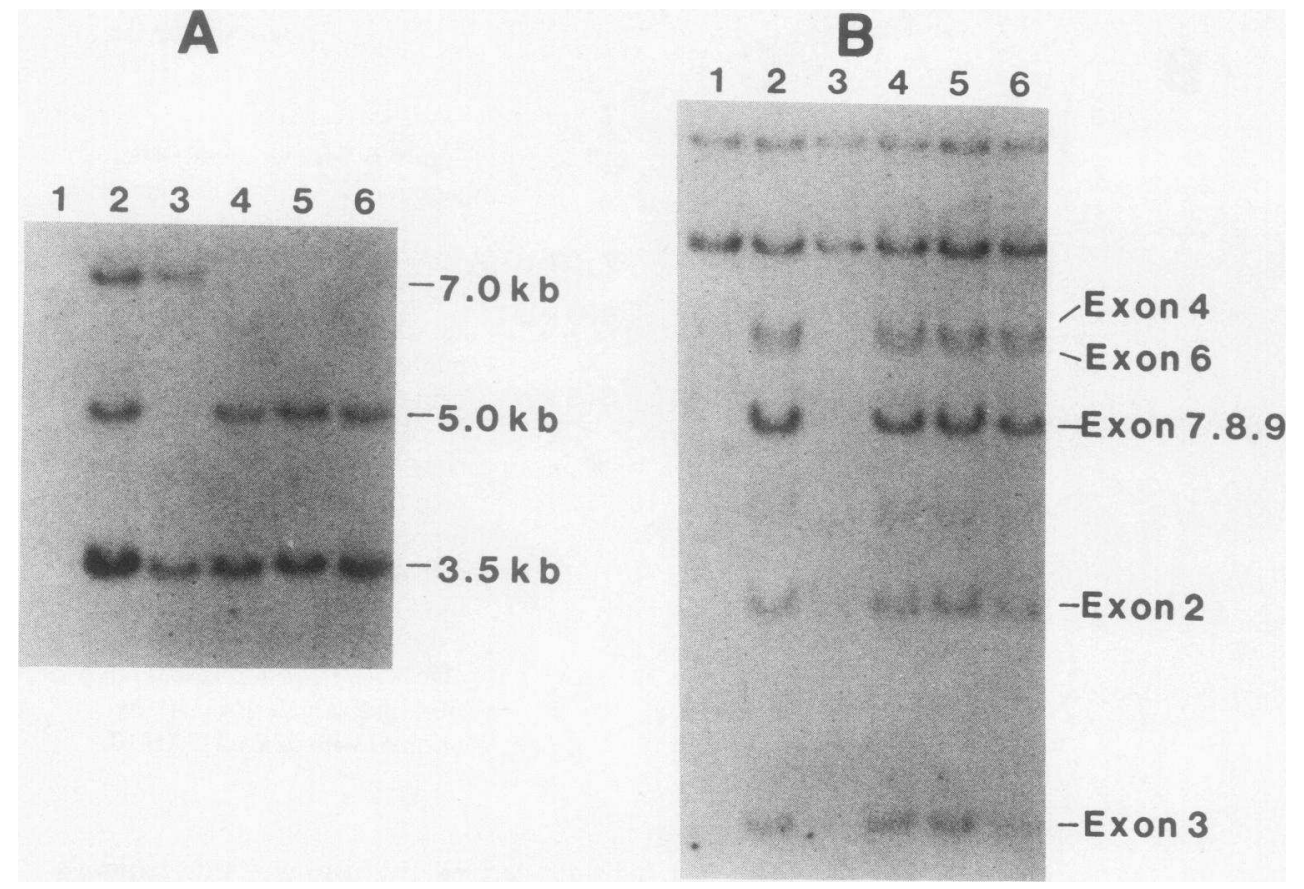

Figure 2. Southern blot analysis of DXS-10 and HPRT gene loci in somatic cell hybrids. Cell lines are those described in Table I. $(A)$ Taq I-digested DNA probed with labeled DSX-10 DNA. Lane 1, mouse L Tk DNA; lane 2, FLN-1 DNA; lane 3, FLN-6 DNA; lane 4, FLN-7 DNA; lane 5, FLN-3 DNA; lane 6, FLN-4 DNA. (B) Pst-digested DNA probed with labeled HPRT cDNA. Lanes correspond to those in $(A)$.
Since functionally hemizygous female carriers of the Lesch-Nyhan syndrome remain disease free, another factor besides the microdeletion must have been crucial to pathogenesis in this patient. We studied the possibility that preferential inactivation of the paternal $\mathrm{X}$ chromosome or selection against an active paternal $\mathrm{X}$ chromosome contributed to this patient's disease. Preferential inactivation of the paternal $X$ chromosome was investigated through study of the previously described mouse human hybrids. We studied the expression of two X-linked enzymes that flank HPRT, PGK and G-6-PD. In hybrids that contained both the paternal and maternal $X$ chromosomes (FLN-1 and FLN-2) both human PGK and G-6-PD were expressed (Fig. 3, lane 2; Table I). Both enzymes were also expressed in the single hybrid that contained only the maternal X chromosome (Fig. 3, lane 3; Table I). In six independently derived clones that carried only the paternal $\mathrm{X}$ chromosome, no human PGK or G-6-PD were detected (Fig. 3 , lanes 4-6; Table I). These data indicate that nonrandom inactivation of the paternal $\mathrm{X}$ chromosome and a microdeletion of the HPRT gene on the active maternal chromosome were responsible for the absence of HPRT in this patient.

To further investigate the potential for nonrandom inacti-

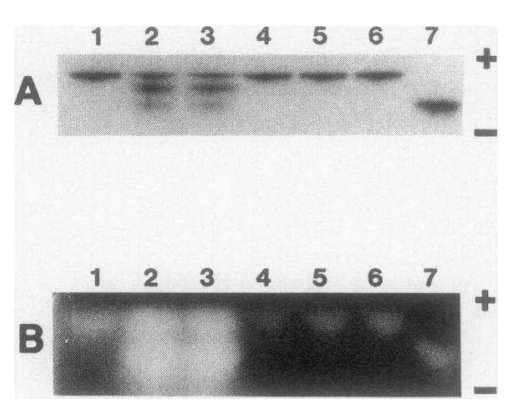

Figure 3. Representative G-6-PD $(A)$ and PGK $(B)$ analysis of hybrid cells. Lanes 1-6 correspond with cell lines described in Fig. 2 $A$; lane 7 represents a human fibroblast control. The more anodal bands represent mouse protein, the more cathodal bands represent human protein, and the intermediate bands are heteropolymers. vation of the paternal $X$ chromosome in this patient we examined patterns of methylation within the first intron of the HPRT gene in genomic DNA from the father and the patient. Two CpG-rich regions within the HPRT gene are important in HPRT gene regulation. One region, within the first intron of the gene, includes four sites that are unmethylated when carried on the active $\mathrm{X}$ chromosome and methylated when carried on the inactive $X$ chromosome $(21,22)$. Thus, methylation-sensitive restriction enzymes can be used to differentiate between active and inactive HPRT genes. Active HPRT loci are associated with a 9.5-kb Bam HI-Hpa II fragment derived from the first intron of the HPRT gene. While Southern analysis demonstrated that this fragment was present in genomic DNA from the father, it was not observed in similarly treated DNA from the patient, in keeping with an active HPRT locus in the father and an inactive HPRT locus in the patient (data not shown).

\section{Discussion}

Cultured fibroblasts and hair follicles can be used to demonstrate that random $\mathrm{X}$ inactivation results in mosaicism for HPRT activity in carrier females; some cells contain the $X$ chromosome that bears the mutant HPRT allele, while others carry the normal $X$ chromosome (19). This mosaicism is not as evident in lymphocytic cells from proven heterozygotes, presumably because of an in vivo selection against HPRT-deficient cells in the presence of normal lymphocytes. Thus, our finding of a female Lesch-Nyhan hemizygote who had exclusive inactivation of an apparently normal HPRT gene in all cells studied was unusual. This may reflect a breakdown in the normal $\mathrm{X}$ inactivation pathway in females. Usually the paternal $X$ chromosome undergoes $X$ inactivation during spermatogenesis and is then reactivated after conception. Random inactivation of either the maternal or paternal $X$ occurs during female embryogenesis $(23,24)$. The genes responsible for these events are not yet defined. Because our patient had a de novo deletion of undetermined size, the possibility that loci near the 


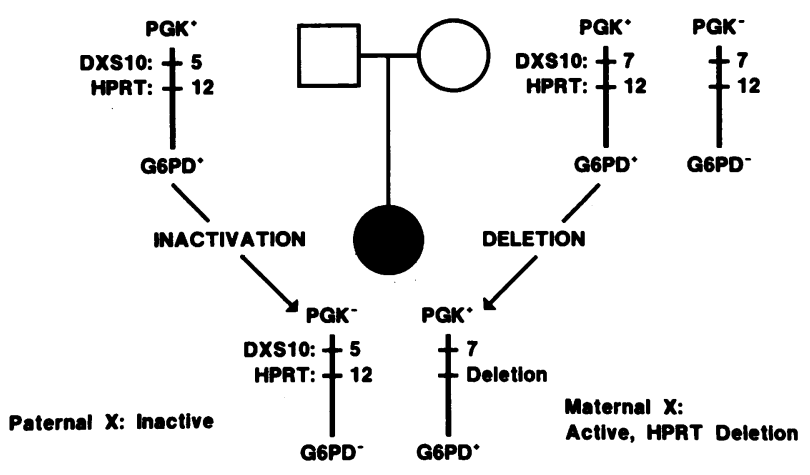

Figure 4. Proposed summary of pathogenesis for the female LeschNyhan patient.

HPRT gene that affect paternal $X$ activation must be considered. Neither of two other hemizygous carriers in our patient population with a complete HPRT gene deletion showed any evidence of disease, but the extent of their deletions was not defined. It is intriguing to speculate that the two rare events seen in this patient, HPRT gene deletion and nonrandom $X$ inactivation, were related. In this regard it will be interesting to examine other female carriers of HPRT gene deletions for $\mathrm{X}$ inactivation bias, perhaps as determined by the timing of $\mathrm{X}$ chromosome replication. Alternatively, this patient's disease may reflect a selection against an active paternal $\mathrm{X}$ chromosome; however, there is no evidence to suggest that the father had an X-linked disease or that the paternal X chromosome in the patient is cytologically abnormal.

Here we report the identification of a female with the $\mathrm{X}$ linked recessive Lesch-Nyhan syndrome and suggest that her disease was the result of a microdeletion of the HPRT locus within the maternally derived $\mathrm{X}$ chromosome and selective inactivation of or selection against the paternal $\mathrm{X}$ chromosome. A schematic summary of the proposed mechanism of pathogenesis is shown in Fig. 4. A thorough understanding of the factors involved in $\mathrm{X}$ inactivation and reactivation is needed to define this novel mechanism of expression of an $\mathrm{X}$-linked recessive disorder in a female. How general this mechanism may be to other loci is unresolved as this is the first published example.

\section{Acknowledgments}

This work was supported by a Gout Research Foundation grant and an Intractable Disease grant from the Ministry of Health and Welfare of Japan (to Dr. Ogasawara), by the Howard Hughes Medical Institute (to Dr. Caskey), National Institutes of Health grant AM-31428 (to Dr. Caskey), and the Philip Michael Berolzheimer Medical Scientist Training Fellowship (to Dr. Stout).

\section{References}

1. Jacobs, P. A., P. A. Hunt, M. Mayer, and R. D. Bart. 1981. Duchenne muscular dystrophy (DMD) in a female with an X:autosomal translocation: further evidence that the DMD locus is at X-21. Am. J. Hum. Genet. 33:513-518.

2. Bodrug, S. E., P. D. Ray, I. L. Gonzalez, R. D. Schmickel, J. E. Sylvester, and R. G. Worton. 1987. Molecular analysis of a constitutional X-autosome translocation in a female with muscular dystrophy. Science (Wash. DC). 237:1620-1624.

3. Gilchrist, G. S., D. Hammond, and J. Melnyk. 1965. Hemophilia A in a phenotypically normal female with XX-XO mosaicism. N. Engl. J. Med. 273:1402-1406.

4. Nisen, P., J. Stamberg, R. Ehrenpreis, S. Velasco, A. Shende, J.
Engelberg, G. Karayalcin, and L. Waber. 1986. Medical intelligence: the molecular basis of severe hemophilia B in a girl. N. Engl. J. Med. 315:1139-1142.

5. Bithell, T. C., A. Pizarro, and W. D. MacDiarmid. 1970. Variant of Factor IX deficiency in female with 45,X Turner's syndrome. Blood. 36:169-179.

6. Therman, E., C. Denniston, G. E. Sarto, and M. Ulber. 1980. $\mathrm{X}$-chromosome constitution in the human female phenotype. Hum. Genet. 54:133-143.

7. Lesch, M., and W. L. Nyhan. 1964. A familial disorder of uric acid metabolism and central nervous system function. Am. J. Med. 36:561-570.

8. Seegmiller, J. E., F. M. Rosenbloom, and W. N. Kelley. 1967. An enzyme defect associated with a sex-linked human neurological disorder and excessive purine synthesis. Science (Wash. DC). 155:16821684.

9. Wilson, J. M., G. E. Tarr, W. C. Mahoney, and W. N. Kelley. 1982. Human hypoxanthine guanine phosphoribosyltransferase: complete amino acid sequence of the erythrocyte enzyme. J. Biol. Chem. 257:10978-10985.

10. Kelley, W. N., and J. B. Wyngaarden. 1983. Clinical syndrome associated with hypoxanthine guannine phosphoribosyltransferase deficiency. In The Metabolic Basis of Inherited Disease. J. B. Stanbury, J. B. Wyngaarden, J. L. Frederickson, J. L. Goldstein, and M. S. Brown, editors. 5th ed. McGraw-Hill Inc., New York. 1115-1143.

11. Patel, P. I., P. E. Framson, C. T. Caskey, and C. A. Chinault. 1986. Fine structure of the human hypoxanthine phosphoribosyltransferase gene. Mol. Cell. Biol. 6:393-403.

12. Haldane, J. B. S. 1935. The rate of spontaneous mutation of a human gene. J. Genet. 31:317-326.

13. Szybalski, W., and E. H. Szybalska. 1962. Drug sensitivity as a genetic marker for human cell lines. Univ. Mich. Med. Cent. J. 28:277-293.

14. Brennand, J., A. C. Chinault, D. S. Konecki, D. W. Melton, and C. T. Caskey. 1982. Cloned cDNA sequences of the hypoxanthine guanine phosphoribosyltransferase gene from a mouse neuroblastoma cell line found to have amplified genomic sequences. Proc. Natl. Acad. Sci. USA. 79:1950-1954.

15. Boggs, B. A., and R. L. Nussbaum. 1984. Two anonymous $\mathrm{X}$-specific human sequences detecting restriction fragment length polymorphisms in the region X126-qter. Somatic Cell Mol. Genet. 10:607-613.

16. Beutler, E. 1969. Electrophoresis of phosphoglycerate kinase. Biochem. Genet. 3:189-195.

17. Motulsky, A. G., and A. Yoshida. 1969. Methods for the study of red cell glucose-6-phosphate dehydrogenase. In Biochemical Methods in Red Cell Genetics. J. J. Yunis, editor. Academic Press, New York. 51.

18. Ogasawara, N., S. Kashiwamata, H. Oishi, K. Hara, K. Watanabe, S. Miyazaki, T. Kumagai, and S. Hakamada. 1984. Hypoxanthine-guanine phosphoribosyl transferase (HGPRT) deficiency in a girl. Adv. Exp. Med. Biol. 165:13-18.

19. Gartler, S. M., R. C. Scott, J. L. Goldstein, and B. Campbell. 1971. Lesch-Nyhan syndrome: rapid detection of heterozygotes by the use of hair follicles. Science (Wash. DC). 172:572-575.

20. Jolly, D. J., A. C. Esty, H. V. Brenard, and T. Friedmann. 1982. Isolation of a genomic clone partially encoding human hypoxanthine phosphoribosyltransferase. Proc. Natl. Acad. Sci. USA. 79:5038-5041.

21. Locke, L. F., D. W. Melton, C. T. Caskey, and G. R. Martin 1986. Methylation of the mouse HPRT gene differs on the active and inactive X-chromosomes. Mol. Cell. Biol. 6:914-924.

22. Yoffe, G., G. Spitzer, B. A. Boggs, K. B. McCredie, S. A. Stass, and A. C. Chinault. 1987. Determination of clonality in acute nonlymphocytic leukemia by restriction fragment length polymorphism and methylation analysis. Leukemia (Baltimore). 1:226-230.

23. Lyon, M. F. 1972. X-chromosome inactivation and developmental patterns in mammals. Biol. Rev. 47:1-35.

24. Cattanach, B. M. 1975. Control of chromosome inactivation Annu. Rev. Genet. 9:1-18. 